\title{
Primera sección:
}

Inmanencia de las pedagogías

अध 


\section{Una pedagogía de la sensación, Deleuze y el concepto kantiano de lo sublime}

DOI: https://doi.org/10.38017/9789588966458.01

Stephen Zepke ${ }^{1}$

Traducción de Mónica Zuleta (con el apoyo del profesor César Johanny

Suarez Pineda - Departamento de Idiomas Fundación Universitaria Juan de Castellanos) ${ }^{2}$.

Lo sublime parece constituir una especie de punto ciego en la literatura ya considerable, acerca de la relación de Deleuze con Kant. La lectura de Deleuze es inusual, particularmente respecto a 'la doctrina de las facultades' (que es el subtítulo de su libro sobre Kant), que considera "uno de los puntos más originales del kantismo, la idea de una diferencia de naturaleza entre nuestras facultades" $(1984 \text {, p. } 22)^{3}$. Para Deleuze, dicha diferencia adquiere diversas formas de armonía entre las facultades en el kantismo: en las dos primeras Críticas, una facultad legisla sobre las demás, como sucede en los casos de la razón especulativa (el entendimiento) o de la razón práctica. Sin embargo, continúa, la armonía requiere un acuerdo libre e indeterminado entre las facultades, que Kant

1 Licenciado en Estudios Clásicos y Filosofía de la Universidad de Victoria, Wellington, Nueva Zelanda; maestro en Arte e Historia de la Universidad de Auckland, Nueva Zelanda, y doctor en Filosofía de la Universidad de Sidney, Australia. Fue asistente de Eric Alliez, Haron Farocki y Chantal Mouffe. Ocupó cargos en el Instituto de Filosofía de la Universidad de Viena y en la Universidad de Artes Aplicadas. Desde 2009 trabaja como investigador independiente.

$2 \mathrm{~N}$ de $\mathrm{T}$ : se tradujeron las citas al español para dar agilidad a la lectura del texto; muchas se cotejaron con las traducciones al español más conocidas, y se encontraron similitudes salvo algunas palabras que no son determinantes para el sentido de la traducción. Se optó por no cambiarlas. Por ese motivo se dejaron los números de las páginas de los libros en Inglés.

3 En particular, Deleuze se centra en el hecho de que para Kant "es posible la no transición desde lo sensible hasta lo suprasensible" (CJ segunda Introducción, II, 175-6: 14-15/83). 
encuentra en la tercera Crítica, en el caso del juicio estético; y, finalmente, en el 'acuerdo discordante' (Deleuze, 1984) en lo sublime. Deleuze sostiene que el acuerdo discordante redistribuye de manera efectiva las facultades: deja de lado las operaciones de representación del conocimiento mediante la localización de la génesis de la experiencia en la relación directa de la síntesis pasiva de la imaginación -lo que Kant llama "intuición" (Deleuze, 1994, p. 86) - y las ideas de la razón. Según el viejo argumento de Deleuze, de Diferencia y repetición, "la doctrina de las facultades es un componente totalmente necesario al sistema de la filosofía" (1994, p. 143). Lo que casi nunca se discute, al menos que yo sepa, es la forma en que Deleuze utiliza la propuesta de lo sublime, como modelo para su propia imagen poskantiana del pensamiento.

Según nos dicen Deleuze y Guattari con aprobación, la Crítica del juicio es "una obra sin restricciones, de la vejez", entre otras cosas, porque en ésta "todas las facultades de la mente superan sus límites, los mismos límites en los que Kant había puesto tanto cuidado en sus primeras obras" (1994, p. 2). Esta 'inversión' de Kant conseguida, como veremos más adelante, gracias al concepto de lo sublime, es quizás el ejemplo más extremo de la ventriloquía filosófica de Deleuze, un método de tierna violencia que crea un "nuevo" Kant o, incluso, como Alberto Toscano ha sugerido, un "Kant que se vuelve contra Kant" (2006, p. 197) ${ }^{4}$. El mismo Deleuze dice, cuando habla de su relación con Kant, "una buena destrucción requiere de amor" (2004, p. 139). La desfiguración de Kant por Deleuze lo revive al mismo tiempo como una figura para el futuro, y es crucial para toda la filosofía de Deleuze, al establecer ambas cosas: su método crítico y el alcance de sus ambiciones trascendentales.

4 Christian Kerslake llama esto, "el ambivalente Kantianismo de Deleuze", en el que: "El punto no es simplemente criticar a Kant sino hacer justicia por completo para dominar su sistema, de modo que pueda generar todas sus posibilidades, sus armonías más sutiles y sus significados o sentidos más profundos" (2009, p. 82). Más exactamente, y muy correctamente, él dice que Deleuze busca "Una estética Trascendental revisada, en la que la intuición, en su forma intensiva es capaz de hacer una conexión más sutil y diferenciada con el ideal (el espacio de los problemas o las ideas), que Kant parece haber sospechado" (2009, p. 139). 
La lectura de Deleuze comienza a partir de lo que él llama la "formidable dificultad" de entender la "misteriosa" armonía entre las facultades en el sentido común (1984, p. 22). La armonía requiere la presuposición de un sentido común estético que, para Deleuze, es una "solución insatisfactoria" (2004, p. 60), ya que "la Crítica en general demanda un principio para este acuerdo, de la génesis del sentido común" (1984. pp. 22-23). Kant depende de una teoría del sentido común, en la medida que asume como común a todos, a la representación y al modelo representativo de pensamiento, y que atribuye a la subjetividad trascendental como dicho modelo. Según Deleuze -y no es un cumplido-, el sentido común es "una imagen pre-filosófica y natural del pensamiento" (1994, p. 131). Una vez que el objeto ha sido representado a través de las síntesis empíricas de la imaginación y del esquematismo del entendimiento, las otras facultades reflejan su identidad subjetiva. Deleuze señala que el acuerdo entre las facultades es "una constante de la Crítica kantiana" (2004, p. 57), aunque no esté exento de varias negociaciones y disputas. El entendimiento determina la razón para un propósito especulativo (de acuerdo con un sentido común lógico), mientras que la razón legisla sobre el entendimiento por propósitos prácticos (según un sentido común moral), y cada uno produce juicios determinantes - "Este $\mathrm{x}$ (singular) es del tipo $\mathrm{X}$ (universal)"-. Para Deleuze, lo anterior

conduce a Kant a otro problema: las facultades nunca llegarían a un acuerdo fijo o determinado por una de ellas si, para empezar, ellas no fueran en sí mismas y de forma espontánea capaces de un acuerdo indeterminado, de una armonía libre, sin ningún tipo de proporción fija. [...] ¿Cómo podría cualquier facultad, que es legislativa para un propósito particular, inducir a las otras facultades a llevar a cabo tareas indispensables y complementarias, si todas las facultades juntas no fueran, en primer lugar, capaces de un acuerdo libre y espontáneo, sin legislación, sin propósito, sin predominancia? (2004, p. 58).

En este sentido, la tercera Crítica "destapa el fondo presupuesto por las otras dos Críticas: un acuerdo libre de las facultades" (Deleuze, 2004, p. 58), y, de hecho, "constituye el fundamento original del que 
se derivan las otros dos Críticas [ ...] acuerdo libre, indeterminado e incondicional" (p. 69). El acuerdo entre las facultades es libre en el juicio estético, porque nuestros sentimientos, en estos casos, no son determinados todavía por un interés empírico, especulativo o práctico, y no conciernen a fenómenos (legislados por el entendimiento), o a noúmenos (legislados por la razón), sino solo legislan sobre sí mismos (son heautónomos). Sin embargo, Deleuze dice: "aquí es donde la verdadera dificultad de la Crítica del juicio comienza: ¿cuál es la naturaleza de este sentido común estético?" (p. 60). Nosotros no podemos afirmar esta de manera lógica (es decir, a través de las categorías) ni postularla (lo que la determinaría prácticamente), por lo que parece que solo se puede presumir. Y para Deleuze, lo anterior es altamente insatisfactorio, ya que el sentido común estético actúa como fundamento de las demás relaciones entre las facultades y de los juicios que producen. Kant debe mostrar, entonces, cómo se produce el acuerdo libre entre las facultades $y$, al hacerlo, debe ir más allá, y revelar las condiciones de la experiencia que hacen posible su "génesis trascendental" (Deleuze, 2004, p. 61).

Deleuze afirma que la Analítica de lo Bello se queda corta y requiere de la Analítica de lo Sublime que le sigue. En este punto, las cosas empiezan a ponerse interesantes, ya que, si bien el juicio de lo sublime revela la mayor armonía de las facultades de la imaginación y la razón, esta armonía es profundamente "paradójica" (2004, p. 61), ya que emerge de su "desgarramiento doloroso" (p. 62). Ese "desgarramiento" es resultado de que la imaginación es incapaz de reflejar la forma de su experiencia "sublime", a pesar de que la razón demanda que unamos la infinitud del mundo en su conjunto. La razón, como "la facultad de lo infinito" (Deleuze, 1978b), "obliga a la imaginación a confrontar su límite" (2004, p. 62). Sin embargo, es en este acuerdo con la razón, "paradójico" y violento, que la experiencia encuentra su génesis trascendental, que descubre lo que el entendimiento había mantenido en secreto, a saber, el destino suprasensible de la imaginación, que también es como un origen trascendental (Deleuze, 2004, p. 62). Deleuze sostiene que, en lo sublime, la imaginación despierta la razón como la facultad 
capaz de "concebir un sustrato suprasensible para la infinitud del mundo sensible" (p. 62); la razón tiene ideas de lo infinito y, de esta manera, la imaginación se eleva a su función trascendental. Deleuze argumenta que todas las formas de juicio estético descubren el "origen trascendental" de la imaginación en las ideas de la razón; en el acuerdo de la Naturaleza y la armonía de las facultades, primero, en lo bello, que, dice, "utiliza el modelo proporcionado por la sublime" (2004, p. 64); segundo, en el símbolo, el cual es posible, porque "fue necesario pasar por el modelo genético de la Sublime" (p. 66); y tercero, en el genio, que "es la disposición subjetiva a través de la cual, la naturaleza da reglas al arte", y es también "un modo de presentación de las ideas" (p. 67).

Mientras que lo bello, el símbolo y el genio operan a través de la armonía de la imaginación y el entendimiento, que encuentra su génesis trascendental en la razón; la experiencia sublime, que es su modelo, es el resultado de la falla de la síntesis empírica de la imaginación, y, por consiguiente, de su armonía 'libre' con el entendimiento (que no juega ningún papel en lo sublime). La función de la imaginación trascendental, como revela el juicio estético de lo sublime, es ir más allá de los límites legislados por las otras facultades, dada su imposibilidad de representar noúmenos. Aunque la imaginación solamente trasciende esta imposibilidad en un aspecto negativo en lo sublime, logra una "abstracción" que marca una "expansión del alma" (Kant, citado en Deleuze, 2004, p. 62). Como Deleuze señala, esa "abstracción-expansión" expresa precisamente la génesis suprasensible de la imaginación, aquello que comparte con la razón y el entendimiento, y que garantiza la "unidad suprasensible de todas las facultades" (p. 63). Una vez más, se trata de una extraña especie de "unidad", donde las facultades que lo sublime pone en juego apuntan a una génesis de su acuerdo dentro de la discordia inmediata (p. 63).

\subsection{Cuatro inversiones filosóficas}

Fiel a los gustos de Deleuze de "destrucción con amor", el prefacio de la traducción en inglés de 1984 de la Filosofía crítica de Kant, esboza cuatro "inversiones" filosóficas. Tres de estas, Deleuze se las atribuye 
a Kant: su nueva comprensión de la forma del tiempo, el efecto del tiempo en el sujeto, y la forma de la Ley moral; mientras que una -el uso no regulado de las facultades- aunque Deleuze la encuentra en Kant, opera en contra del propio sistema de Kant, una "inversión" final que es, de hecho, "propia" de Deleuze. Todas estas inversiones emergen del método "crítico" de Kant, "un acontecimiento tremendo en la filosofía”, afirma Deleuze (1978), mediante el cual el pensamiento examina su propio funcionamiento con miras a comprender sus condiciones de posibilidad. La consecuencia de lo anterior, continúa Deleuze, fue un cambio de perspectiva que condujo a que la filosofía crítica dejara de preocuparse por lo que se encuentra fuera de la experiencia (independientemente de que sea el objeto o la esencia), para interesarse solo en la naturaleza de esa experiencia, y buscara, más bien, sus condiciones trascendentales (en tanto inmanentes). Por consiguiente, el método crítico es el punto de partida y el ímpetu de las otras "inversiones", la primera de las cuales concierne al tiempo. En Kant, el tiempo deja de ser parte del movimiento, como sucedía en la filosofía antigua, y pasa a convertirse en la forma dentro de la cual el movimiento se determina (Deleuze, 1984). Esta es la emergencia de una "conciencia moderna del tiempo" (Deleuze, 1978), donde el tiempo "es la forma de todo lo que cambia y se mueve, pero es una forma inmutable que no cambia- no una forma eterna, sino precisamente, la forma de lo que no es eterno, la forma inmutable del cambio y el movimiento" (Deleuze, 1997, p 28, véase también 1984: viii). El tiempo, en este sentido, es la primera de las condiciones trascendentales del pensamiento porque, a partir de ese momento, pensar contiene una distinción absoluta entre lo que aparece en la intuición "antes de todo pensamiento" (Kant CPR B132: 153/136) y la forma de su determinación como pensamiento, que es tiempo ${ }^{5}$.

5 Para Kant, independientemente de su origen, todas las representaciones como modificaciones de la mente, deben pertenecer al sentido interno. Todo nuestro conocimiento está así finalmente sujeto al tiempo, la condición formal del sentido interno. En el tiempo, deben estar ordenadas, conectadas y relacionadas (A98/9). 
La toma de consciencia de esta forma de tiempo es lo que Kant llama "apercepción" o el "yo pienso" que, según Deleuze, va más allá que la fórmula de Descartes, "pienso, luego soy". Deleuze dice que "nada es más instructivo que la diferencia entre el cogito Kantiano y el Cartesiano" (1994, p. 85), y es importante ver por qué. Kant argumenta que si bien es razonable decir -como lo hizo Descartesque la determinación ("yo pienso") implica algo indeterminado que será determinado ("yo soy"), no es posible concluir de ello "yo soy una cosa que piensa", porque no sabemos la forma en que lo indeterminado va a ser determinable por la determinación. Kant rellena el eslabón perdido y muestra que -en paráfrasis de Deleuze"la forma bajo la cual el 'yo soy' es determinable es, obviamente, la forma del tiempo" (1978a, n.p). Eso introduce lo que Deleuze llama la "paradoja del sentido interior" (1978a, n.p) en la que "yo pienso" es una determinación activa de mi existencia, pero solo puede determinar mi existencia bajo la forma de lo determinable; es decir, bajo la forma de un ser pasivo en el espacio y en el tiempo (1978a, n.p). En suma, mientras que la determinación conceptual puede muy bien proporcionar las condiciones conceptuales de la experiencia posible, el espacio y el tiempo, reclama Deleuze, "serán la potencia constitutiva de toda experiencia posible" (1978, n.p). La apercepción trascendental (el "yo pienso", forma sine qua non del tiempo), proporciona la condición real de ambos, de la posibilidad conceptual y del pensamiento representacional. Su descubrimiento es, para Deleuze, la contribución más importante de Kant a la filosofía, aún si es por razones que el mismo Kant no desarrolla enteramente.

Para Deleuze, la consecuencia dramática de lo anterior es la fórmula "Yo es otro", obtenida de Rimbaud, que usa para describir la segunda "inversión” de Kant y que, según él, constituye el "aspecto más difícil" de "la revolución kantiana" (1984, p. viii). Difícil porque el sujeto está dividido irreductiblemente, está fracturado, debido a que el "yo" de la "síntesis pasiva" de la intuición (como Deleuze lo llama), y la subjetividad trascendental del "yo pienso", constituido por la "síntesis activa" del entendimiento, están "separados por la 
línea de tiempo que los relaciona entre sí, pero bajo la condición de su diferencia fundamental" (1984, p. viii). Dice Deleuze que, mientras la síntesis pasiva da una sensación que me fuerza a pensar, es un "imperativo" para pensar, "los imperativos entran y salen solamente por la fractura en el yo, lo que significa que otro piensa siempre en mí, otro que debe también ser pensado" (1994, p. 200). Desde esta lectura de Deleuze, entonces, el tiempo no funda la subjetividad trascendental ni el objeto constituido por el "sentido común" de las facultades, como desea Kant, sino que nos sumerge en la paradoja irreductible del sentido interno, donde "nuestra interioridad constantemente nos separa de nosotros mismos, nos divide en dos: un desdoblamiento que nunca sigue su curso, ya que el tiempo no tiene fin. Un vértigo, una oscilación, constituye el tiempo" (Deleuze, 1984, p. ix).

\subsection{Las tres síntesis de tiempo}

En Diferencia y repetición, Deleuze elabora esa división de la interioridad en términos de tres síntesis de tiempo. La primera es "la síntesis original, que opera en la repetición de los instantes” (1994, p. 71), una síntesis enteramente pasiva ejecutada por la "imaginación" que constituye y repite instantes sensibles como un hábito (aquí Deleuze sigue a Hume) o "lo que Kant llama la receptividad de la intuición" (p. 86). Deleuze le da el nombre de "primera síntesis del tiempo", que entiende como una "contemplación contráctil" o una repetición habitual de instantes que constituye lo que está siendo vivido, la experiencia viva, el presente (p. 70) de un "yo pasivo", un "yo" que retiene lo suficiente de sus instantes precedentes para formar las expectativas que constituyen "una regla de vida para el futuro" (p. 71). El yo pasivo emerge de estos "eventos" de "contemplación", de estos contactos misteriosos de lo sensible y la sensibilidad, de la experiencia y lo que la origina ${ }^{6}$. Deleuze

6 En este sentido, nosotros somos sensibles "hasta el fondo" en la medida que las síntesis perceptivas se refieren a las síntesis orgánicas que son como la sensibilidad de los sentidos, una sensibilidad primaria que nos constituye (y a todo lo demás). En este nivel, el presente vivido está constituido por un pasado de herencia celular y por un fututo de necesidad (Deleuze, 1994, p. 73). 
localiza la diferencia entre Kant y Hume precisamente en ese nivel de la imaginación. Hume asume un dualismo irreductible (y, por lo tanto, empirista) entre los objetos de la naturaleza y su experiencia, mientras que Kant asume su acuerdo (racionalista) sobre la base de una "síntesis trascendental pura de la imaginación como la condición de la posibilidad misma de toda experiencia" (CPR A101: 133/164). Esta síntesis trascendental establece a la experiencia como representacional, y a los objetos de la experiencia (noúmenos, o "cosas en sí mismas") como fuera de las condiciones de la experiencia posible o conocimiento. Bajo este régimen de representación, Deleuze señala en su libro sobre Hume:

Lo dado no es una cosa en sí, sino más bien un conjunto de fenómenos, un conjunto que puede ser presentado como naturaleza solamente por medio de una síntesis a priori. Esto último hace posible una regla de representaciones dentro de la imaginación empírica sólo bajo la condición de que primero constituya una regla de los fenómenos dentro de la propia naturaleza. Por lo tanto, para Kant, las relaciones dependen de la naturaleza de las cosas en el sentido de que, como fenómenos, las cosas presuponen una síntesis cuya fuente es la misma que la fuente de las relaciones (1991, p. 111).

En otras palabras, las cosas presuponen a la representación que es el "dogma" de Kant (como Deleuze lo llama). No obstante, según Deleuze, la teoría de Kant de la síntesis del tiempo (es decir, "la apercepción") sobre la cual el dogma está basado, conduce también a que el dogma colapse y a que emerja lo real en su lugar.

La repetición de instantes como hábito por la "imaginación espontánea” (1994, p. 77), constituye un presente que pasa (desde el presente pasado hasta el presente futuro); pero, argumenta Deleuze, si este es el caso, debe haber entonces otro momento en el que el presente pasa. Esta es la síntesis pasiva de la memoria, "más profunda" (1994, p. 80) (la segunda síntesis del tiempo, de acuerdo con Deleuze), que forma el pasado desde la autoconciencia pasiva del yo como una serie de presentes anteriores (es decir, como hábito). En este momento, el presente anterior se encuentra 
"representado" en sí mismo, y, al mismo tiempo, está también representado como presente, o "reflejado" ahí (p. 80). Por lo tanto, la memoria es la síntesis trascendental del pasado puro, que hace posible que el presente se convierta en el pasado, para que el tiempo emerja como tal, y, por lo tanto, para que la apercepción sea posible. A través de la memoria, la reproducción del pasado y la proyección del futuro se vuelven posibles, de acuerdo con las síntesis activas de contigüidad, la causalidad, la semejanza o la oposición, encontradas en el entendimiento (p. 83). Deleuze no trata de negar la representación, sino muestra cómo esta depende de las síntesis pasivas de la imaginación (hábito y memoria) y, por consiguiente, cómo la representación tiene una génesis empirista en lugar de racionalista. Deleuze se refiere a su propia filosofía como "empirismo trascendental".

Deleuze pregunta si es posible vivir las síntesis pasivas de la memoria: ¿es posible vivir el "ser en sí del pasado", tal como hacemos las síntesis pasivas del hábito que constituyen nuestros cuerpos orgánicos, sin reducirlas a un momento histórico o una experiencia subjetiva, sin subordinarlas a la representación que de hecho traicionan? La única forma de hacerlo es mediante la afirmación de la diferencia trascendental que divide el pasado "en sí" y el presente de la experiencia vivida, lo que no significa "resolver" o "disolver" esta diferencia, sino permitir que resuenen. Este es el método del empirismo trascendental, un método sublime porque lleva a la imaginación más allá de sus límites, más allá de su determinación por las síntesis activas, hacia las ideas que habitan en el "en sí" del tiempo y proveen las condiciones de su génesis trascendental (Deleuze los llama 'problemas'). Deleuze escribe: el presente solo formula una "pregunta persistente, que se desarrolla dentro de la representación como un campo de problemas con el imperativo riguroso, de buscar, de responder, de resolver" (1994, p. 85).

Deleuze acomoda las facultades de las síntesis pasivas y activa de una manera kantiana, puesto que "las síntesis activas de la memoria y del entendimiento están superpuestas sobre y soportadas por la 
síntesis pasiva de la imaginación" (1994, p. 71). Del mismo modo, el concepto de Kant de "apercepción trascendental" -la forma del tiempo que permite que sea determinado lo determinable-- es la condición formal que faculta que el yo pasivo experimente su propio pensamiento, "en virtud del cual puede decir yo" (1994, p. 86). Al hacerlo, sin embargo, esta "forma vacía del tiempo" la tercera síntesis del tiempo en el relato de Deleuze- divide las síntesis pasivas de la imaginación que constituyen la presencia pura de la experiencia (lo indeterminado) de la síntesis activa que las representa como la experiencia de un sujeto consciente (determinación). El resultado de lo anterior es que la forma vacía del tiempo (en cuanto la forma de lo determinable) realiza ambas cosas: divide y conecta las síntesis pasiva y activa, más exactamente, las conecta dividiéndolas. La tercera síntesis del tiempo es una síntesis disyuntiva que reúne las contracciones pasivas de la sensación (hábito) y el pasado puro que las contiene (memoria), con las síntesis activas de una auto-conciencia conceptual (el acto). La síntesis solo funciona a través de la cesura que impone entre sus términos, una relación paradójica en la que el sujeto activo es, a la vez, constituido y disperso. Como dice Deleuze, la tercera síntesis "se refiere a la ausencia de fundamento en la que nosotros nos precipitamos al propio fundamento" (p. 114), y alcanzamos "lo sin forma como el producto de la más extrema formalidad" (p 115). Deleuze describe lo anterior como la victoria pírrica del Cogito de Kant, porque a la vez que establece el tiempo como la forma que une las facultades, establece su diferencia irreductible del noúmeno incognoscible. Al "invertir" esta relación, al hacer que la síntesis pasiva se vuelva constitutiva de la realidad (en lugar de la representación que condena la realidad a lo suprasensible), Deleuze convierte la síntesis disyuntiva de las facultades, la "forma vacía del tiempo", en la génesis del pensamiento (como lo es en Kant), pero el pensamiento crea ahora la realidad (en cuanto ser) en lugar de simplemente representarla. Así, mientras Deleuze conserva las facultades, estas ya no se someten a la armonía del sentido común, $y$, en cambio, encuentran su génesis trascendental en una disyunción no regulada y violenta. En palabras de Deleuze, las síntesis pasiva y activa: 
poseen una coherencia secreta que excluye aquella del yo; vuelven la espalda contra el yo que se ha convertido en su igual y lo rompen en pedazos, como si el portador del nuevo mundo se dejara llevar y se dispersara por el choque de la multiplicidad a la que da a luz: lo que el yo ha convertido en igual, es en sí lo desigual (1994, pp. 89-90).

En este sentido, la condición a priori del pensamiento es precisamente lo que no puede ser pensado, porque la tercera síntesis del tiempo garantiza la coherencia del sujeto racional de Kant solo mediante el establecimiento de su génesis, como un a priori dentro de la patología inconsciente de la síntesis pasiva. Como Deleuze señala, esto es una "inversión" de Kant que emerge en un "momento preciso dentro del kantismo, un momento furtivo y explosivo que ni siquiera se prolonga en Kant" (1994, p. 58). Esa inversión corresponde al momento en que el cogito se precipita en su propio abismo, "una alienación de derecho, insuperable por derecho" (p 58) que, Deleuze dice, proporciona "un cogito para un yo disuelto" (p. 58). Esta "esquizofrenia caracteriza la más alta potencia del pensamiento", una potencia que "abre el Ser directamente hacia la diferencia" (p. 58). Experimentar este "yo disuelto" es tener una "experiencia real" de la disyunción inclusiva a priori del ser y del pensamiento, que se vuelve contra el sujeto trascendental y sus condiciones de la experiencia posible, "lo rompe en pedazos", para que surja, en cambio, el "ya-superhombre, cuyos miembros dispersados gravitan alrededor de la imagen sublime", una imagen que "hace que el sol explote" (p. 89).

La explosión del sol marca el final del sujeto trascendental racional, cosificado por la revolución copernicana de Kant, y la aparición gozosa del superhombre de Nietzsche que toma su lugar. Deleuze ofrece una versión explícitamente nietzscheana de la crítica, al convertir la unidad sintética de la apercepción, descubierta por Kant, en la diferencia ontogénica de la voluntad de poder (síntesis pasiva en cuanto sensación), y su afirmación en el "concepto" del eterno retorno (síntesis activa en cuanto pensamiento) (1994, p. 41). Al seguir este momento furtivo en Kant, Deleuze muestra cómo 
una repetición aleatoria de la diferencia descansa en el corazón mismo de la razón kantiana (1983, p. 52). La "tercera síntesis del tiempo" libera el futuro de cualquier determinación a priori (en particular, de la estructura lógica de causa y efecto, es decir, del tiempo cronológico), para anunciar "la repetición del futuro como eterno retorno" (Deleuze 1994, p. 90). De este modo, Deleuze anota que Nietzsche lleva la crítica más allá del punto en que se "agota en compromisos" (1983, p. 89), del punto en el que el propio Kant fue "la encarnación perfecta de la falsa crítica" (2004, p. 139); funda en cambio una transformación radical del Kantismo, una reinvención de la crítica traicionada por Kant en el mismo momento en que la concebía, una reanudación del proyecto crítico sobre bases nuevas y con conceptos nuevos (Deleuze, 1983, p. 52). Como Deleuze dice en Diferencia y repetición en relación con Nietzsche: "las condiciones de una verdadera crítica y una verdadera creación son las mismas: la destrucción de una imagen de pensamiento que se presupone a sí mismo, y la génesis del acto de pensar en el pensamiento mismo" (1994, p. 139). Esta es una revolución contra la revolución copernicana, que no hace que el sol vuelva, sino que supone su estallido; atañe solo a las nebulosas, se confunde con ellas, no tiene movimiento más que para ellas (Deleuze, 1994, p. 91). Ha surgido una crítica verdadera de Kant, ya no comprometida con la presuposición de las condiciones del pensamiento (es decir, con una imagen representativa del pensamiento), sino con las nebulosas, que distribuye "el acto de pensar en el pensamiento mismo" (p. 139). ¿En qué consiste este acto de pensar?

\subsection{El pensamiento sublime y las ideas problemáticas}

Deleuze nos dice que "el pensamiento" es una formulación nietzscheana maravillosa, que "es, sobre todo, trasgresión y violencia", lo que nos obliga a pensar, un encuentro con "el ser de lo sensible' (1994, p. 139). Este evento fuerza la sensibilidad dentro de un 'juego discordante' con las facultades activas, un "trabajo conjunto" (p. 140) que solo se las arregla para confirmar su diferencia. El ser de lo sensible, lógicamente, solo puede ser sentido, pero, como tal, y antes de que se convierta en un objeto 
-o aún en una cualidad- en síntesis activas, este es, "una sensación cierta de lo imperceptible" (p. 140). La tercera forma del tiempo impone esa paradoja, porque fuerza a las facultades activas o empíricas a su límite mismo, al tiempo que estas intentan captar lo único que puede ser sentido, pero también, que no puede serlo. Aquí, la sensación surge como un problema (p. 140), como un problema sublime, ya que no puede ser representada por las síntesis activas de la conciencia, o captada por cualquiera de las facultades empíricas, y empuja esas facultades hacia su límite, hasta el punto de que Deleuze nos dice "cada facultad se desquicia" (p. 141). No hay más sentido común, no hay más sujeto y objeto unidos en una representación, solo hay una sensación que va más allá de su síntesis activa y que exige, sin embargo, ser pensada. En este momento, la síntesis pasiva de la sensación presenta un "problema" sublime, una "idea problemática", como Deleuze la llama, en tanto una contracción empírica del tiempo mismo en su totalidad.

De acuerdo con Deleuze, esa "idea" extrañamente desorientadora, arrastrada desde el corazón del sistema de Kant, explota el "círculo vicioso que hace que la condición se refiera a la condicionado" (1990, p. 105). Esta es una objeción al sistema de Kant que Deleuze hereda del pos-kantiano. Salomon Maïmon arguye que los principios a priori de la representación se trazaron a partir de estructuras psicológicas de la percepción y, por lo tanto, que fallaron en encontrar la experiencia real y las condiciones genéticas. Si el entendimiento y la sensibilidad son dos fuentes de cognición totalmente independientes, Maïmon pregunta: ¿cómo es que la sensibilidad aparece solamente en los términos del entendimiento? (2010, p. 38). Tal aparición no nos dice nada acerca del lugar de donde proviene la sensación, acerca del noúmeno, que permanece necesariamente acordonado en el sistema de Kant. La solución de Maïmon -que Deleuze sigue- es postular que las intuiciones 'formales' de espacio y tiempo proveen la materia a la sensación que posee una magnitud intensiva determinada por diferenciales. Maimön se basa en Leibniz para argumentar que el espacio y el tiempo no son formas absolutas e ideales de la intuición, sino son 
dos formas diferentes de diferenciación necesarias para que los seres finitos sientan un objeto como tal. Como resultado, podemos tener una experiencia real de lo infinito, intensiva y auto-diferenciada, pero solo desde la perspectiva limitada del ser sensible, lo que deja la mayor parte de este reino nouménico en la oscuridad y las sombras. Las magnitudes diferenciales que componen la sensación no pueden ser captadas por representaciones o por el pensamiento conceptual, sino forman 'Ideas del entendimiento' como Maïmon las llama, o noúmenos que solo aparecen posteriormente como representaciones. Para Maimön -y para Deleuze después de élla diferencia en cuanto sensación es real, como tal puede pasar a través de la barrera que Kant fijó entre fenómenos y noúmenos, y puede ser seguida desde los objetos hasta sus diferencias genéticas a través del uso de ecuaciones diferenciales. Como dice Deleuze,

la genialidad de Maïmon consistió en mostrar lo inadecuado que es para la filosofía trascendental, el punto de vista del condicionamiento: los dos términos de la diferencia deben ser igualmente pensados -en otras palabras, la determinabilidad debe ser concebida en sí misma como apuntando hacia un principio de determinación recíproca (1994, p. 173).

Maïmon localiza el condicionamiento dentro de las sensaciones intensivas, y Deleuze ve también la sensación como diferencial y como condicionamiento, y la identifica con las ideas 'problemáticas' del pensamiento que se encuentran en la facultad de la razón. Como hemos visto, para Deleuze, la síntesis activa es consecuencia de la síntesis pasiva, lo que hace que la razón -o como prefiere llamarlo Deleuze, "el pensamiento"- sea una ubicación más conveniente del condicionamiento o la génesis trascendental.

La única manera de descubrir los principios trascendentales de la génesis, es asumir que la intuición pasiva de la sensación precede y condiciona la síntesis activa, ya que, como Deleuze señala, "el empirismo trascendental es la única manera de evitar que se trace lo trascendental dentro de los contornos de lo empírico" (1994, p. 144). En otras palabras, solo el empirismo trascendental es capaz de llevar cada facultad hasta su límite, al sintetizar "estados libres o 
salvajes de diferencia en sí misma” (p. 144). Deleuze afirma que la tercera Crítica de Kant anticipa esas objeciones "al menos en parte", puesto que "descubre el fundamento último que faltaba en las otras dos Críticas" (2004, p. 61). El fundamento que es descubierto es el acuerdo "libre, indeterminado e incondicional", entre las facultades, lo que significa que "con la Crítica del juicio, entramos en la Génesis" (pp. 68-9). En este punto, cada facultad emerge por sí misma, sin restricciones y libre de ir hasta su límite, si bien, sin embargo, en armonía con las demás, una cooperación en la que se establece la necesidad de cada una. Aquí, la síntesis pasiva (sensación) emerge en una relación libre con una variedad de facultades, lo que les permite desarrollar 'extrañas combinaciones' (1984, p. xii) dentro de su "acuerdo discordante, [como] la fuente del tiempo" (1984, p. xiii).

Esta es la cuarta inversión que Deleuze "encuentra" en Kant, una vez más, obtenida de Rimbaud: "un trastorno de todos los sentidos o, más bien, un ejercicio no regulado de las facultades” (1984, p. xi). Deleuze asocia directamente esta "desregulación" de las facultades con lo sublime, que va más allá de la armonía de las facultades a la idea de totalidad que expresa, pero porque esta desregulación se aplica a todas las facultades y a la Idea problemática que condiciona a cada una de ellas, esta discordia deviene la condición del pensamiento. "Discordia de las facultades", Deleuze clama, "cadena y mecha explosiva en la que cada una experimenta su límite, y no recibe de la otra (o no comunica a la otra), sino una violencia que la pone cara a cara con su propio elemento, como ante su disparidad o su incomparable" (1994, p. 141). Lo "dispar" o lo "incomparable" de la facultad es una descripción sucinta de la paradoja sublime que constituye la génesis trascendental de cada facultad, la Idea problemática o "elemento diferenciador" (p. 142) que la facultad intenta captar, pero no puede. Como Deleuze señala, esta idea es "la violencia de aquello que la fuerza a ejercitarse; de aquello que está forzada a captar; de aquello que, sin embargo, es también lo que no se puede captar (desde el punto de vista del ejercicio empírico)" (p. 143). Las facultades no reguladas también se multiplican 
con la adición de Deleuze de las facultades de la imaginación de Kant (como se le suele entender), el lenguaje, la vitalidad y la sociabilidad, junto con otras "que aún no han sido descubiertas". Cada facultad se desarrolla en torno a su límite; silencio para el lenguaje, anarquía para la sociabilidad, etc., cada uno es la Idea problemática responsable de la génesis trascendental de la facultad.

Esta Idea es sensación, como hemos visto, pero es una sensación sin extensión, sin un cuerpo o un signo que la representa. Es una intensidad que Kant definió como una sensación captada en su diferencia de cero absoluto, y que Deleuze dilucida como lo que crea, a la vez, la cualidad en lo sensible y el ejercicio trascendental en la sensibilidad (1994, p. 144). Esta intensidad diferencial, que es imperceptible empíricamente por lo que debe ser esquematizada primero en un objeto, es "percibida" por la síntesis pasiva (intuición) que la aprehende inmediatamente en el encuentro. Como Deleuze dice: "El privilegio de la sensibilidad como origen aparece en esto: que lo que fuerza a sentir y lo que solo puede ser sentido son una y la misma cosa en el encuentro, mientras que las dos instancias son distintas en otros casos" (pp. 144-145). Mientras que la síntesis activa solo puede representar las intensidades como extensión, las "Ideas" son capaces de pensar las intensidades como un "problema". Este "pensamiento" inherente a las "Ideas" viene directamente de Kant, para quien la razón opera a través de la toma de los fenómenos del entendimiento y del intento de moverlos, de lo condicionado a su condición, de descubrir los principios incondicionados que los fundamentan. En sus palabras: "La mente escucha la voz de la razón dentro de sí misma, que exige la totalidad para todas las magnitudes dadas” (CJ\$26 254: 111/177).

7 Una vez más, Deleuze sigue muy cercanamente a Kant; "Kant nunca cesó de recordarnos que las ideas son esencialmente "problemáticas" (1994, p. 168). O de nuevo: "Kant fue sin lugar a dudas el primero en aceptar lo problemático no como una incertidumbre fugaz sino como el objeto de la idea y por tanto, como un horizonte indispensable de todo lo que sucede o aparece" (1990, p. 54). En este sentido, la razón es la facultad que plantea problemas, en la medida que sus objetos están por fuera de la experiencia posible y, por tanto, que solo pueden ser planteados como problemas. 
La razón opera de acuerdo con las reglas del juicio: trata de esquematizar "Ideas" de una totalidad problemática como la condición incondicionada de los conceptos empíricos. Kant reconoce que este proceso de la razón da lugar a la ilusión trascendental (o antinomia), que lo incondicionado puede ser dado; $y$, en lugar de cuestionar si la razón funciona de acuerdo con las reglas del juicio, (es decir, si es representacional), decide en cambio, sustraer el elemento incondicionado y genético de la experiencia (el noúmeno) del ámbito de la representación.

Deleuze, sin embargo, "invierte" ese conjunto de relaciones, y busca la génesis de la representación en los "problemas" que representa el entendimiento conceptual y que resuelve o, quizás mejor, que actualiza. En este sentido, la aplicación de un concepto en un juicio está guiada por un "problema" como la "estructura" intensiva consistente, que permite que se encarne en una "cosa". Como tal, las ideas problemáticas se convierten en noúmenos, en tanto que "fundamento" de la experiencia, pero este "fundamento" no es indiferenciado ni es inmutable (como el noúmeno inaccesible de Kant). Es una sensación intensiva y diferencial que actúa como el "acontecimiento" genético de la experiencia, un destello de perspectiva sobre el todo abierto (o el ser) del que proviene, y que se expresa en una individuación única. Deleuze mantiene, por tanto, la distinción entre fenómenos y noúmenos, pero la replantea, como la síntesis activa y la pasiva, como lo actual y lo virtual, o como la experiencia y la idea problemática, y establece como genética su diferencia trascendental, en la medida que crea el acontecimiento de la sensación. Según Deleuze, Kant no construyó una "lógica de lo sensible", sino más bien una estética "en donde lo sensible es válido en sí mismo y se desarrolla en un pathos más allá de toda lógica, que capta el tiempo en su surgimiento, en el origen mismo de su hilo y su vértigo" (1984, p. xiii). Dice (no sin cierta satisfacción) que la lógica de lo sensible es una inversión impactante, y bastante "contraria a Kant" (1994, p. 143), incluso si es Kant quien la elabora.

Deleuze le da un giro a Kant, al argüir que el noúmeno es sensación, que no solamente es un acontecimiento en cuanto genético, 
sino que es además determinable por fuera de los límites de la representación, a través del cálculo diferencial. "La diferencia no es fenómeno, pero el noúmeno es cercano al fenómeno" (Deleuze, 1994, p. 280); la diferencia produce los fenómenos internamente e inmanentemente, o, en otras palabras, es genética. Según SomersHall, el cálculo diferencial "permitirá [a Deleuze] postular en contra de Kant, la posibilidad de determinaciones que, aunque estrictamente no son nada en relación con la representación, sin embargo, no son estrictamente nada" (2009, p. 145). Estas determinaciones son Ideas, o más precisamente, el pensamiento es la actualización de las Ideas como la individua[t]ión del ser mismo.

En tanto "pensamiento" problemático de una totalidad que está por fuera de la experiencia subjetiva, pero que, sin embargo, actúa como su condición genética, una Idea es una cuestión de sentido más que de cognición, y del cuerpo más que de la conciencia. Las ideas proporcionan una "unidad" sistémica a las facultades que no resuelven sus diferencias irreductibles, sino les proporcionan "estructuras" intensas que dan coherencia a la experiencia ${ }^{8}$. Las ideas son, entonces, los pensamientos de un Cogito disuelto, que

repiten los tres aspectos del Cogito: YO SOY como una existencia indeterminada, EL TIEMPO como la forma bajo la cual esta existencia es determinable, y el YO PIENSO como una determinación. [Las Ideas ...] son indeterminadas con respecto a su objeto, son determinables en cuanto a los objetos de la experiencia, y portan el ideal de una determinación infinita con respecto a los conceptos del entendimiento (1994, p. 169).

Como mostré antes, según Deleuze, dicho pensamiento explota el centro estelar del sujeto trascendental, lo ahoga en la variabilidad, enfrenta el pensamiento con sus condiciones reales en tanto

8 Mientras Deleuze describe el pensamiento como un "amor" que atraviesa y conecta varias facultades, este también implica una 'cólera' que define una 'situación revolucionaria' que, según él, "causa que la idea explote en lo actual" (1994, p. 246). Esta aparición excesiva es también una destrucción amorosa de los límites de las "facultades", o lo que él llama también una "ocasión sublime" (1994, p. 190). 
problemas, y exige soluciones que, como señala Deleuze, son "compuestas de mil maneras diferentes" (1994, p. 169). Con una sonrisa descarada, Deleuze admite que "quizás esto no aparece suficientemente claro en Kant” (p. 170).

Sin embargo, la Idea problemática sí aparece en Kant, aparece en lo sublime. Deleuze sostiene que allí, la Idea surge de los restos de la subjetividad trascendental, capaz de ser "pensada" por una imaginación que, finalmente, se desató del entendimiento. Escribe Deleuze,

la imaginación esquemática de la Crítica de la razón pura está todavía bajo la lógica del sentido común; la imaginación reflexiva del juicio de lo bello está todavía bajo el sentido común estético. Sin embargo, en lo sublime, de acuerdo con Kant, la imaginación es forzada o constreñida a enfrentar su propio límite, su phantasteon, su máximo, que es igualmente el inimaginable, lo informe o lo deformado en la naturaleza (CJ\$26). Más aún, la imaginación transmite esta restricción al pensamiento mismo, que a su vez se ve obligado a pensar en lo suprasensible como la fundación de ambos, de la naturaleza y de la facultad de pensar: el pensamiento y la imaginación entrar aquí en una discordancia esencial, en una violencia recíproca que las condiciona a un nuevo tipo de acuerdo (CJ§27) (1994, p. 321).

En otra parte, Deleuze arguye,

la armonía entre las facultades sólo puede aparecer bajo la forma de una armonía discordante, ya que cada una se comunica con la otra solamente por medio de la violencia que la confronta con su propia diferencia y con su divergencia respecto a las otras. Kant fue el primero en proporcionar el ejemplo de una tal armonía discordante, la relación entre la imaginación y el pensamiento que se produce en el caso de lo sublime (1994, p. 146, cursiva agregada).

En lo sublime, entonces, Kant descubre una facultad no regulada por el sentido común y, por lo tanto, dispuesta a explorar su ejercicio trascendente en el ámbito de las Ideas. 
Deleuze argumenta que las Ideas son "estructuras suprahistóricas" y virtuales que se actualizan mediante un "génesis estática", un "suceso" que "puede entenderse como el correlato de la síntesis pasiva” (1994, p. 183). Por lo tanto, una Idea surge cuando se cumplen ciertos criterios estructurales y genéticos que son específicos para el dominio de su llegada, pero no están determinados por dicho dominio, no son fijos, y son superados continuamente como una facultad que se desarrolla más allá de sus límites anteriores. Como dice Deleuze, los dos elementos de una Idea virtual y su actualización son 'ecos que no se parecen entre sí, puesto que, "las series ideales gozan de la doble propiedad de la trascendencia y la inmanencia en relación con lo real" (p. 189). Por lo tanto, la Idea es actualizada como el momento creativo / crítico, el momento cuando el pensamiento descubre sus condiciones reales para sobrepasar sus límites, sus condiciones reales son diferencia (la Idea diferencial) que el pensamiento actualiza en devenir. Estos son los momentos de transformación, los momentos de revolución, los momentos de una síntesis pasiva completamente indeterminada cuyo suceso da lugar a un acto. Este suceso, exclama Deleuze, es "una ocasión sublime [...] que hace que la solución explote como algo abrupto, brutal y revolucionario. Tener una idea es esto también" (p. 190).

\subsection{Presentación negativa y el sentimiento-intelectual de lo sublime}

La significación de lo sublime, para Deleuze, es la manera en que la Crítica del juicio hace colapsar la determinación conceptual de la experiencia que se encuentra en la Crítica de la razón pura. Ese colapso anuncia una nueva relación entre la imaginación y la razón que se encuentra en la experiencia estética, un "sentimiento intelectual" [Geistesgefühl] (CJ, segunda Introducción 192: 32/103) que resulta de la 'sintonía mental' de la imaginación y la razón en lo sublime. El "sentimiento intelectual” de lo sublime es consistente con el entendimiento de Deleuze de la lectura de Nietzsche sobre la crítica: "El punto de la crítica no es una justificación, sino una manera diferente de sentir: otra sensibilidad" (1983, p. 94). Este "sentimiento" o sensación es muy inusual, ya que la experiencia 
sublime excede nuestra capacidad para representarlo, y nos causa dolor, al mismo tiempo que encontramos dentro de nosotros mismos el poder de la razón y las ideas, que son capaces de pensar ese exceso, y nos causan placer. Por lo tanto, lo sublime es una experiencia de este "disenso" (Deleuze, 1984, p. 51), una experiencia intensa de la "violencia recíproca" (Deleuze, 1994, p. 321) que constituye su "sentimiento-intelectual", y la manera -un tanto masoquista- de encontrar "la armonía en el dolor" (2004, p. $62)$.

Todas estas formulaciones apuntan hacia el papel de la presentación negativa en el sublime, hacia el hecho de que las síntesis activas del esquematismo no pueden representar las ideas producidas por lo sublime, que solo pueden aparecer como la ausencia de lo que es esencialmente impresentable. Hasta ahora, muy de Kant. Pero Deleuze insiste en la materialidad de las ideas, en su existencia problemática como la génesis intensa de la síntesis pasiva, $y$, por lo tanto, como la sensación misma. Los "sentimientos-intelectuales sublimes" no sufren de una falta de presencia, sino de su exceso, estos están demasiado presentes para la síntesis activa de la representación, que no puede captarlos dentro de la estructura de la consciencia, del pensamiento lógico. Lo sublime es, por lo tanto, necesario para revelar esta inadecuación, y para forjar una conexión (aunque en una presentación negativa) entre la intuición y el infinito, a través de un "signo" expresivo de la síntesis pasiva, de una fuerza genética que debe sentirla (pero que no puede). Como dice Deleuze, hay "en esta presencia excesiva, la identidad de un yaaquí y de un siempre con retraso" (2003, p. 51, cursiva agregada), lo que significa que "la semejanza surge como el producto brutal de medios no semejantes" (p. 115). Dicha sensación es lo que experimentamos cuando se han superado nuestras condiciones de la experiencia posible, pero cuando esta sensación aparece, se evapora simultáneamente, ya que la idea de infinito que 'piensa' no puede aparecer en su sentimiento-intelectual. La sensación actualiza la idea infinita, $y$, al hacerlo, da una presentación, una "expresión analógica" como Deleuze la llama en su libro sobre Francis Bacon, 
de lo que no puede ser presentado. En esta medida, entonces, dicha sensación "analógica", que expresa esto no es eso, va más allá de las condiciones en que la experiencia posible encuentra una síntesis activa, porque manifiesta sus condiciones reales en cuanto síntesis pasiva, en y como experiencia, en últimas, porque experimenta sus condiciones reales en una experiencia real. La sensación sin forma de un infinito que la excede enteramente, es el estatuto paradójico de un "sentimiento-intelectual" sublime; aunque implica la presentación negativa, no está confinada ni definida por lo negativo. Por otro lado, la presentación negativa es la presentación positiva de lo que no puede ser representado, y, como tal, es negativa solo en relación con la síntesis activa, dado que la actualización que causa que lo actual difiera de sí mismo (es decir, la Idea problemática), el sentimientointelectual sublime, es totalmente positivo, y es la presencia de un infinito no actual, sino genético. Dice Deleuze que "el sin sentido", "no es la ausencia de la significación, sino, por el contrario, el exceso de sentido" (2004b, p. 187). Entonces, una sensación sublime "piensa" la diferencia en sí en cuanto infinito virtual, no como un objeto, sino como un "problema" que arrastra lo virtual en la materia, donde no es "él mismo" (y por lo tanto se "presenta negativamente"), por lo que sólo puede ser presentado como "otra cosa”. Se trata de una 'otra cosa' trascendental y permanente, podemos decir, que está presente solo como el "todavía no", como el futuro de la tercera síntesis del tiempo, como lo nuevo. Este sentimiento-intelectual articula sus estructuras ideales, las explora y las extiende, pero nunca las agota -y ciertamente nunca es esto- en un proceso de creación material.

Este proceso de creación material también anima el arte, o tal vez mejor es arte, cuyas obras, dice Deleuze, "se desarrollan alrededor o sobre la base de una fractura que no puede nunca tener éxito en ser llenada" (1994, p. 195). En este sentido, entonces, la pintura trata de hacer visibles, las fuerzas invisibles, al igual que la música trata de hacer audibles las fuerzas no sonoras, o que el cine "busca acceder a lo que no puede ser pensado en el pensamiento" (Deleuze, 1989, p, 168), y la poesía intenta articular "la palabra secreta que no tiene sentido" (Deleuze, 1994, p. 291); cada arte desarrolla su problema 
único (es decir, su condición trascendental) en sensaciones (sentimientos-intelectuales) de su propia diferencia que lo define. Deleuze admite una "ontología moderna" de las artes, que busca sus propias condiciones a priori a través de un proceso de "crítica" inmanente. Mientras que en la superficie puede parecer que este proceso termina con el descubrimiento de las condiciones a priori que determinan un arte (el color y la línea para las artes visuales, el lenguaje para la poesía, el movimiento y el tiempo para el cine, etc.), estas condiciones suministran más bien, el material específico de experimentación para cada arte, que sufre cambios radicales y mutaciones, en tanto actualiza su estructura y su 'problema' genético. Como señalan Deleuze y Guattari,

Es aquí que el arte accede a su auténtica modernidad, que simplemente consiste en la liberación de lo que estaba presente en el arte desde sus inicios, pero estaba oculto en fines y objetos, aún si son estéticos, y por debajo de recodificaciones y axiomáticas: el proceso puro que cumple en sí mismo, y que no deja de llegar a su plenitud a medida que avanza - arte como "experimentación" (1983, pp. 370-371).

La forma modernista por excelencia es la serie, tal como ésta emerge del proceso modernista de experimentación constante. Deleuze adscribe claramente a un entendimiento vanguardista del arte, pero con la importante salvedad de que su 'modelo' es de-subjetivizado, des-historizado y 'universalizado', como el modelo para la vida misma. En este sentido, "no hay otro problema estético que el de la inserción del arte en la vida cotidiana” (1994, p. 293), la más breve declaración que hizo Deleuze sobre las políticas del arte. Para él, el Modernismo es un proceso de crítica que descubre sus condiciones solo por ir más allá de sus límites anteriores, solo al actualizar sus propios problemas, sus propias ideas, que siempre se le escapan, como el borde del infinito creativo y abierto. A diferencia de nuestra comprensión usual del Modernismo, Deleuze no ve este proceso como un "arte" puro, que gracias a su "pureza" puede emerger como nuevo y autónomo, muy al contrario, lo que es "moderno" en cada arte, es precisamente su habilidad de creación permanente. 


\section{Referencias}

Deleuze, G. (1978). Kant: synthesis and time (Trad. McMahon, M.). http://www.webdeleuze.com

Deleuze, G. (1978a). Second lesson on Kant (Trad. McMahon, M.). http://www.webdeleuze.com

Deleuze, G. (1978b). Fourth lesson on Kant (Trad. McMahon, M.). http://www.webdeleuze.com

Deleuze, G. (1983). Nietzsche and Philosophy. (Trad. Tomlinson, H.) Columbia University Press.

Deleuze, G. (1984). Kant's Critical Philosophy, The Doctrine of the Faculties (Trad. Tomlinson, $\mathrm{H}$ and Habberjam, B). University of Minnesota Press.

Deleuze, G. (1989). Cinema 2, The Time-Image (Trad. Tomlinson, H. and Galeta, R.). University of Minnesota Press.

Deleuze, G. (1990). The Logic of Sense (Ed. Boundas, C. V.). Columbia University Press.

Deleuze, G. (1991). Empiricism and Subjectivity, An Essay on Hume's Theory of Human Nature. (Trad. Boundas, C. V.). Columbia University Press.

Deleuze, G. (1994). Difference and Repetition. (Trad. Patton, P.). Columbia University Press.

Deleuze, G. (2003). Francis Bacon: the logic of sensation (Trad. Smith, D.). Continuum.

Deleuze, G. (2004). Desert Islands and Other Texts 1953-1974. (Ed. Lapoujade, D.). Semiotext(e).

Deleuze, G. y Guattari, F. (1983). Anti-Oedipus, Capitalism and Schizophrenia (Trads. Hurley, R., Seers, M. y Lane, H. R.). University of Minneapolis Press. 
Kant, I. (1929 [1st ed 1781, 2nd ed. 1787]). Critique of Pure Reason (Trad. Kemp, N.). Macmillan.

Kant, I. (1956). Kritik der reinen Vernunft (Ed. Weischedel, W., Vols. 3 and 4 in Suhrkamp's paperback edition). Suhrkamp.

Kant, I. (1987 [1790]), Critique of Judgment (Trad. Pluhar, W. S.). Hackett Publishing Company.

Kant, I. (1956). Kritik der Urteilskraft (Ed Weischedel, W., Vol. 10 in Suhrkamp's paperback edition). Suhrkamp.

Kerslake, C. (2009). Immanence and the Vertigo of Philosophy, From Kant to Deleuze. Edinburgh University Press.

Toscano, A. (2006). The Theatre of Production, Philosophy and Individuation between Kant and Deleuze. Palgrave Macmillan. 